\title{
Natural Lavas as Catalysts for Efficient Production of Carbon Nanotubes and Nanofibers**
}

\author{
Dang Sheng Su* and Xiao-Wei Chen
}

Fritz-Haber-Institut der Max-Planck-Gesellschaft, Faradayweg 4-6, 14195 Berlin (Germany)

* Corresponding author: Fax: (+49) 30-8413-4401, E-mail: dangsheng@fhi-berlin.mpg.de

** This work was performed in the framework of ELCASS (European Laboratory for Catalysis and Surface Science).

The authors thank Dr. Andreja Gajovic, Zagreb, for Raman measurements. We also thank Dr. Nenad Tomasic, Zagreb, Dr. Thomas Hansen, Dr. Jian Zhang, and Prof. Robert Schlögl, Berlin, for helpful discussions.

Keywords: carbon, immobilization, lava rocks, nanostructures

Nanocarbons, especially carbon nanotubes and nanofibers CNTs/CNFs), are key materials in nanoscience and nanotechnology, but their application on a large scale (for instance in catalysis) is limited by their difficult production. Current processes including preparation of the support, normally silica or alumina, and impregnation with catalytically active metal for hydrocarbon decomposition, are not suitable for mass production. Herein we report on the fabrication of CNTs/CNFs on Mount Etna lavas used both as support and as catalyst, the first step for industrial production without preparation of support and its wet-chemical treatment.

Mount Etna is the highest and most active volcano in Europe. The eruptions in 2002 and 2003 were the most explosive eruptions in recent years. On November 12, 2002, the local newspaper "La Sicilia" estimated the volume of emitted lava to be about 10-11 million cubic meters, while the volume of tephra exceeded 20 million cubic meters. The Mount Etna lavas are slightly evolved forms of an alkaline series (trachybasalts and alkali basalts) exhibiting a porphyritic texture with abundant phenocrysts of plagiocalase and fewer clinopyroxene and olivines.[1] The main components are $\mathrm{Si}\left(\mathrm{SiO}_{2} 48 \mathrm{wt} \%\right), \mathrm{Al}, \mathrm{Mn}, \mathrm{Mg}, \mathrm{Ca}, \mathrm{Na}$, and $\mathrm{Fe}\left(\mathrm{Fe}_{2} \mathrm{O}_{3}\right)$.[1] The total amount of $\mathrm{Fe}_{2} \mathrm{O}_{3}$, as high as $11 \mathrm{wt} \%$, is distributed among silicate phases and FeTi oxides.[1] The presence of iron oxide particles in Etna lava makes it an ideal material for growing and immobilizing nanocarbons. Metal particles such as Fe are necessary for the catalytic growth of CNTs/CNFs.[2] They catalyze the decomposition of the carbon source and control the growth kinetics of the tubes/fibers.[3]

The Mount Etna lava used in the present work was collected on the north flank of Etna on November 23, 2003 (Figure 1a). Examination by scanning electron microscopy reveals macropores and mesopores in the silicate matrix (see Figure 1b). The pores contain metal oxide particles ranging from 10 to $100 \mu \mathrm{m}$ in diameter, giving the bright contrast in Figure $1 \mathrm{~b}$. The lava stone was broken into small pieces with a hammer and ground in a mortar. The crushed lava powder (200 $\mathrm{mg}$, the size of the small pieces is less than $0.5 \mathrm{~mm}$ ) was put into a vertical quartz reactor and reduced with $\mathrm{H}_{2}$ at a flow rate of $50 \mathrm{mLmin}^{-1}$ at a temperature of $700{ }^{\circ} \mathrm{C}$ for $2 \mathrm{~h}$. After reduction, a mixture of ethylene and $\mathrm{H}_{2}$ (total flow rate was $200 \mathrm{mLmin}^{-1}$, 50 vol\% $\mathrm{C}_{2} \mathrm{H}_{4}$ ) was introduced into the reactor. The temperature of the lava powder was kept at $700{ }^{\circ} \mathrm{C}$ in the flow gas at atmospheric pressure for $2 \mathrm{~h}$. The color of the lava powder changed to black after the catalytic chemical vapor deposition process (CVD). The iron oxides are reduced to metallic iron by $\mathrm{H}_{2}$ and catalyze the decomposition of ethylene for growing CNTs/CNFs.

The scanning electron micrograph in Figure 1c shows the CNTs/CNFs immobilized on the surface of Etna lava. The transmission electron micrograph in Figure 1d indicates a carbon nanotube with an inner wall diameter of less than $10 \mathrm{~nm}$. Representative Raman spectra of the lava powder, recorded before and after the catalytic CVD process, are shown in Figure 1e. The 


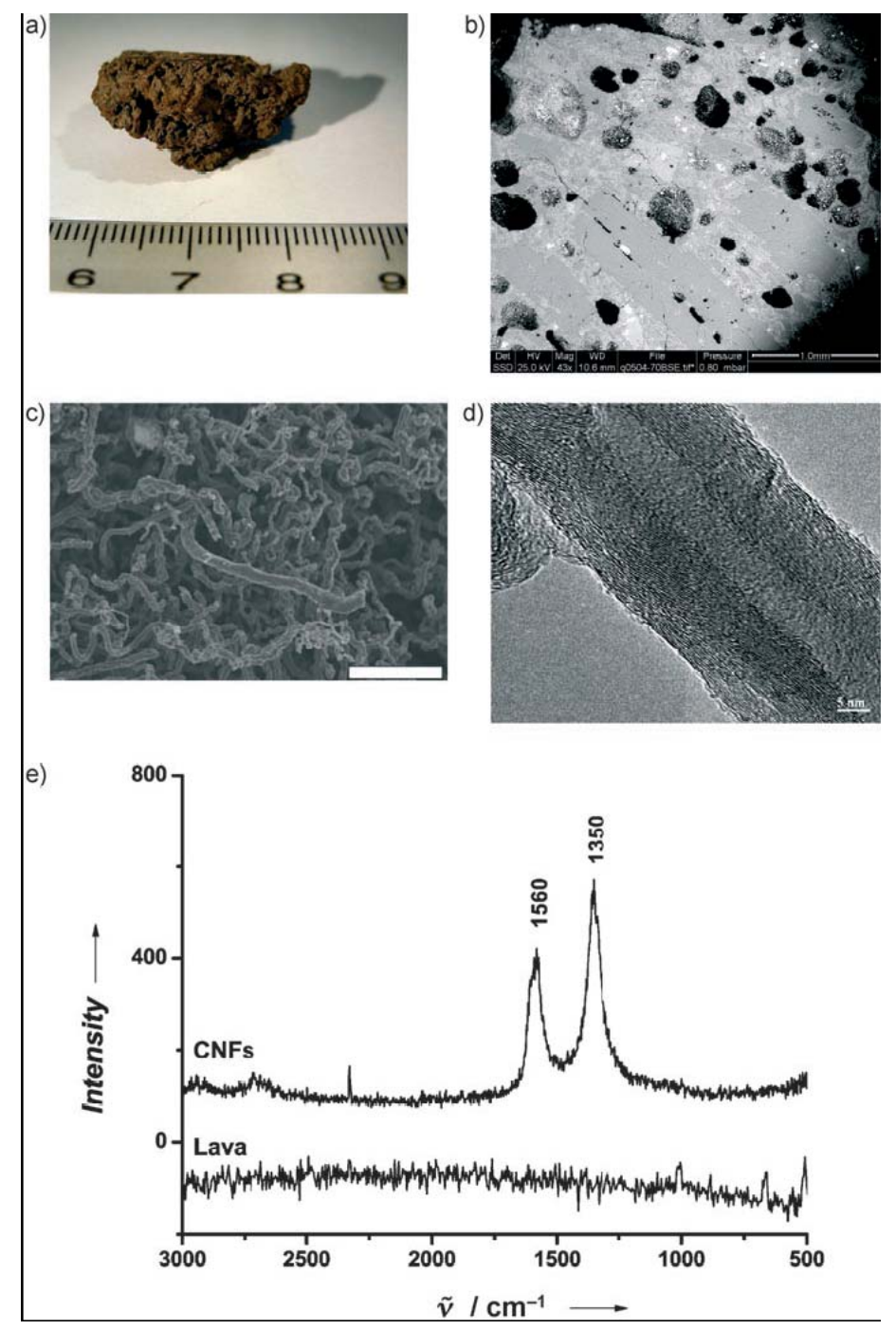

Figure 1. Fabrication of CNTs/CNFs on Mount Etna lava.

a) A piece of lava collected on the north flank of Mount Etna.

b) Cross-section backscattering electron micrograph of Etna lava. The bright contrast is due to metal oxide particles. Scale bar: $1.0 \mathrm{~mm}$. c) Scanning electron micrograph showing carbon nanotubes and nanofibers grown on ground lava stones powder after decomposition of ethylene. The BET surface area of the product is $109.2 \mathrm{~m}^{2}$ $\mathrm{g}^{-1}$, while that of the raw lava before CNT/CNF deposition is $0.027 \mathrm{~m}^{2} \mathrm{~g}^{-1}$. The temperatureprogrammed reduction of lava stone shows there is no weight loss of lava stone up to $700^{\circ} \mathrm{C}$. Scale bar: $3 \mathrm{~mm}$.

d) Transmission electron micrograph of a carbon nanotube showing a parallel multiwalled structure. Scale bar: $5 \mathrm{~nm}$.

e) Raman spectra of lava stones before and after CVD.

spectrum of lava the stone exhibits no characteristic bands of carbon. This indicates that no carbon is deposited during Etna's eruptions, even though the temperatures are high and metal particles are present. After the catalytic CVD process, the G-band at $1560 \mathrm{~cm}^{-1}$ and the D-band at $1350 \mathrm{~cm}^{-1}$, characteristic for $\mathrm{sp}^{2}$-hybridized carbon, appears in Raman spectrum. Fabrication of CNTs/CNFs on naturally occurring minerals without synthetically prepared catalyst could pave the way for further exploitation of the superior properties of tailored nanostructured carbon for large-scale applications, such as catalysis and water purification by adsorption.[4, 5] The crucial point of the present work is that the iron oxide particles abundantly present in minerals can be used as natural catalysts for CNT/CNF growth without any wet-chemical treatment of the support. Since iron exists in a large number of minerals, clays, and soils, a new era may be opened for the cheaper production of immobilized CNTs/CNFs. As mentioned above, Mount Etna lavas are abundantly available in millions of cubic meters.

Our work has another, quite different, aspect, that is, whether CNTs/CNFs can be formed on the million-year evolution of the Earth and the universe. We show that if a carbon source is available, CNTs/CNFs can grow on a mineral at moderate temperatures. Methane gas is emitted from active suboceanic volcanos, and hydrogen is present in volcanic gas. In interstellar space, atomic hydrogen, carbon oxides, and metallic iron are present. These are the prerequisites for CNT/CNF formation. Natural fullerenes have been identified in fulgurite,[6] a glassy rock that forms where lightning hits the ground, and shungite,[7] a highly metamorphosed carbon-rich rock within Precambrian sediments. The remaining question is how to find CNTs/CNFs in nature. 


\section{References}

[1] R. Clocchiatti, M. Condomines, N. GuCnot, J.-C. Tanguy, Earth Planet. Sci. Lett. 2004, 226, 397 - 414.

[2] M. Terrones, Annu. Rev. Mater. Res. 2003, 33, 419 - 501.

[3] P. Coquay, R. E. Vandenberghe, E. De Grave, A. Fonseca, P. Piedigrosso, J. B. Nagy, J. Appl. Phys. 2002, 92, $1286-1291$.

[4] G. Mestl, N. I. Maksimova, N. Keller, V. V. Roddatis, R. SchlHgl, Angew. Chem. 2001, 113, 2122 - 2125; Angew. Chem. Int. Ed. 2001, 40, 2066 - 2068.

[5] D. S. Su, X. Chen, G. Weinberg, A. Klein-Hofmann, O. Timpe, S. B. A. Hamid, R. SchlHgl, Angew. Chem. 2005, 117, 5624 - 5628; Angew. Chem. Int. Ed. 2005, 44, 5488 - 5492.

[6] T. K. Daly, P. R. Buseck, P. Williams, C. F. Lewis, Science 1993, 259, 1599 - 1601.

[7] P. R. Buseck, S. J. Tsipursky, R. Hettich, Science 1992, 257, 215 - 217. 